\title{
Loose Seton: A Misnomer of Cutting Seton
}

\author{
Ugur Sungurtekin1, Murat Ozban1 ${ }^{*}$, Halil Erbis ${ }^{2}$, Onur Birsen ${ }^{1}$ \\ ${ }^{1}$ Department of Surgery, Pamukkale University School of Medicine, Denizli, Turkey \\ ${ }^{2}$ Department of Surgery, Akdeniz University School of Medicine, Antalya, Turkey \\ Email: *muratozban@yahoo.com
}

Received 29 February 2016; accepted 8 May 2016; published 11 May 2016

Copyright (C) 2016 by authors and Scientific Research Publishing Inc.

This work is licensed under the Creative Commons Attribution International License (CC BY). http://creativecommons.org/licenses/by/4.0/

c) (7) Open Access

\begin{abstract}
Purpose: The purpose of this study was to demonstrate loose silk seton actually acts as a slow cutting seton contrary to the idea of simply drainage. Besides, to show the effect of loose seton on patient's incontinence is mostly proportional to the degree of division of the sphincter muscle. Design: Fifty patients with high transsphincteric fistulas were treated with loose seton technique. We measured the length of high sphincteric fistula tracts, pre- and postoperative anal sphincter pressures and incontinence scores. Results: Loose seton with heavy silk resulted in $72 \%$ percent of progressive migration of the fistula tract caudally. The more the progressive migration of the loose seton loop, the less the pressure drop in both resting and squeezing in manometric studies. This study is limited by its retrospective design in prospectively collected data and covers relatively small number of patients. Conclusion: Seton is still useful technique in high perianal fistula surgery. Defining this technique as simply "loose" seton is misnomer since it acts as a slowly cutting seton and results in progressive migration of the fistula tract caudally. The more the progressive migration of the loose seton loop, the less the pressure drop would be possible after postoperatively.
\end{abstract}

\section{Keywords}

Perianal Fistula, Seton, Incontinance, Recurrence

\section{Introduction}

The purpose of the fistula surgery is to eradicate the fistula tract without threatening anal continence. High transsphincteric fistulas may compromise anal continence when they are treated with fistulotomy. Different techniques have been proposed to decrease the risk of postoperative anal incontinence. Seton placement is one of them. Theoretically, seton is an alternative to one-stage fistulotomy, since it performs the division of anal

${ }^{*}$ Corresponding author. 
sphincter muscle more slowly, with a consequent trend towards more preserved sphincter function. Therefore, this technique recommended reduced postoperative anal incontinence in the literature. Loose seton is defined as a ligature made from any type of material placed in the fistulous track around the anal sphincter and tied without tension [1] [2]. The aim of the study is to analyze the effect of loose Seton technique for cryptogenic originated in high transsphincteric anal fistula, on the results of recurrence and its effect on anal pressure changes and postoperative anal incontinence.

\section{Material and Methods}

This prospective study was undertaken of all operations for high transsphincteric anal fistula performed by a single colorectal surgeon (US) from January 2008-November 2010. After obtaining permission from local ethical committee 50 patients (38 male, 12 female) patients with high transsphincteric fistulas treated with loose, 0-heavy silk seton were included to the study. Patient ages were ranging between 18 - 45 years and all patients with primary cryptogenic fistulas were included to this study. Fistulas due to Inflammatory Bowel Disease (IBD), etiological factors other than cryptogenic origins and recurrent fistulas were excluded from the study. Pelvic Magnetic Resonance Imaging (MRI) and rectosigmoidoscopy was performed in all patients due to diagnostic purposes. Anal pressures were measured with fistula probe, pulled through to the internal opening and then pulled through the anus to the outside. The two ends of the silk suture tied loosely. Internal sphincter muscle fibers on the corresponding side of the fistula line did not cut at the first operation. The loose seton was removed electively and staged fistulotomy done two months after unless spontaneous move out occurred before than that time in all cases. All operations were carried out under general anesthesia. All patients were followed by outpatient clinic with questionnaires to discuss the recurrence and incontinence. None of the patients were followed by phone calls. Continence was assessed according to the patients' clinical information and anal manometric changes in anal pressure pre- and posttreatment. Values are expressed as mean \pm s.d.m. Student t test wasused for statistical comparisons. Comparisons between pre- and postoperative groups of manometric variables were made using analysis of variance (ANOVA). A limit of significance ( $p$-value) of 0.05 considered statistically significant.

\section{Results}

The patients' mean age was $28 \pm 1.2$ years (range, 22 - 45 years), with M/F ratio of 3:1. Follow-up ranged from 12 - 36 months (mean, 25 months) and none of the patients were lost in follow-up. The loose seton technique resulted in the gradual healing of the fistula tract in all of patients $(n=50)$, without any recurrence. Loose seton completely worked on their way up to the surface in 11 patients (22\%) and there was no need for a second operation in these patients (Group 1), Although tract migration was present, it was not extensive up to the surface in 39 patients (78\%) (Group 2). These patients were subjected to second (staged) fistulotomy operation. The mean length of the fistula tract was $6 \pm 0.7 \mathrm{~cm}$ at first operation and $3 \pm 0.2 \mathrm{~cm}$ in second operation of this group. The difference between preoperative and postoperative fistula tract length was statistically significant $(p<0.05)$. Pre- and postoperative values of mean resting and squeeze anal pressures for group 1 and 2 are shown. Incontinence rates of the patients evaluated by using the Wexner score values for Group 1 and 2 six months after the operation were 1.3 and 2.1 respectively.

\section{Discussion}

High transsphincteric or suprasphincteric perianal fistula treatment forms a challenge in colorectal surgery. The aim of the treatment was not only to eradicate the fistula, but also keep fecal continence as much as possible. The use of a seton is an ancient treatment method for anal fistulas since Hippocrates [3]. Seton is also used as a passive drainage for perianal fistulas in conditions with an active anal manometric before operation and six month after postoperatively. Pre- and postoperative anal manometric tests were performed using an 8-channel water-perfused, flexible manometer catheter with spirally located perfusion ports for simultaneous balloon inflation and pressure measurement. A computerized system (Solar GI-MMS) was used for patient data acquisition, providing graphical vector volume pressure profiles. The length of the fistula tract was calculated by measuring from outside hole to inside opening by using a $2 / 0$ prolene string during both first and second operation. After measurement; seton with 0 heavy silk suture material inserted from inside into the fistula tract to give a conti- 
nuous drainage of the fistula tract in order to achieve control of sepsis [4]-[6]. Either cutting or loosing seton followed by the two-stage fistulotomy are the most commonly used techniques based on same surgical principles. The cutting seton works as a cutter by tightening the tissue mass around the fistula tract periodically, which is extremely painful. It may have divided the sphincter muscle in an uncontrolled way depending on the squeezing period and the nature of seton material. Loose seton is left around the tissue loosely encircled by the fistula. By the progressive migration of the loosely tied, seton gradually transected the anal sphincter muscles and besides promoted peri-sphincteric fibrosis, thus preventing taking apart of sphincter muscles and decreasing the chances of anal incontinence development in postoperative period [6]. Theoretically known, this information has been proven once again. The loose seton technique resulted in the gradual healing of the fistula tract in all of patients $(\mathrm{n}=50)$, with no recurrence in our study. The sphincter movements during the defecation probably caused a gentle pull down to the anus on the silk seton, resulting in cutting the fistula tract gradually but continually, at the same time becoming the seton looser synchronously. Loose seton completely worked on their way up to the surface in 11 patients (22\%) and there was no need for a second operation in these group of patients (Group 1), Heavy silk was the material of choice for this purpose in our study since it may cause more inflammation than in any inert material used for seton in the literature. Migration of the seton loop occurred in a timeframe equal to two months in our patients. This proved with measured the length of the fistula tract was $6 \pm 0.78$ $\mathrm{cm}$ (first operation) and $3 \pm 0.27 \mathrm{~cm}$ (second operation). This result proved that the loose seton technique by using silk material caused a shortening of the fistula tract length (Figure 1). This is against the idea of loose seton is simply a draining instrument, Besides to this; it has also healing feature by slowly cutting the fistula tract. That is why we called loose seton as a misnomer. In fact, it works as a slow acting cutting seton. Pressure changes in this group was not significant when compared pre- and post-operative values (Figure 2). Division of the rest of the muscle encircled by the fistula tract is then performed as a second (staged) operation after two months. Tract migration was not enough in 39 patients and all of them were subjected to staged fistulotomy (Group 2). Pressure changes in this group were significant when pre- and post-operative values are compared (Figure 3). It has been previously noted that the loose-seton technique could eradicate the fistula track, if the seton was left in place long enough resulting in a slow migration and sometimes expulsion of the seton spontaneously [1] [7]. Nevertheless, we preferred two-month period as a waiting phase for a second stage operation as it was accepted by most of the people [2].

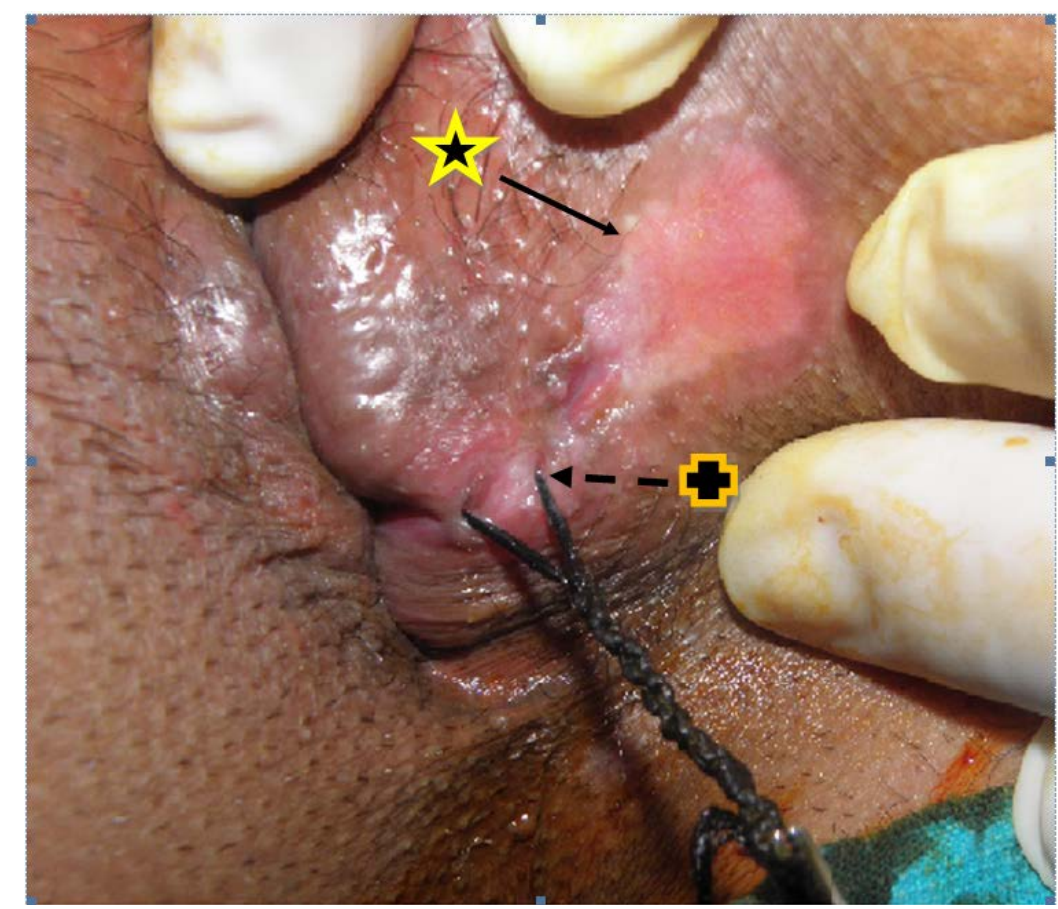

Figure 1. Shortening of the fistula tract length in second operation. $\quad \star$ : External opening site in first operation; $\$$ : External opening site in second operation. 


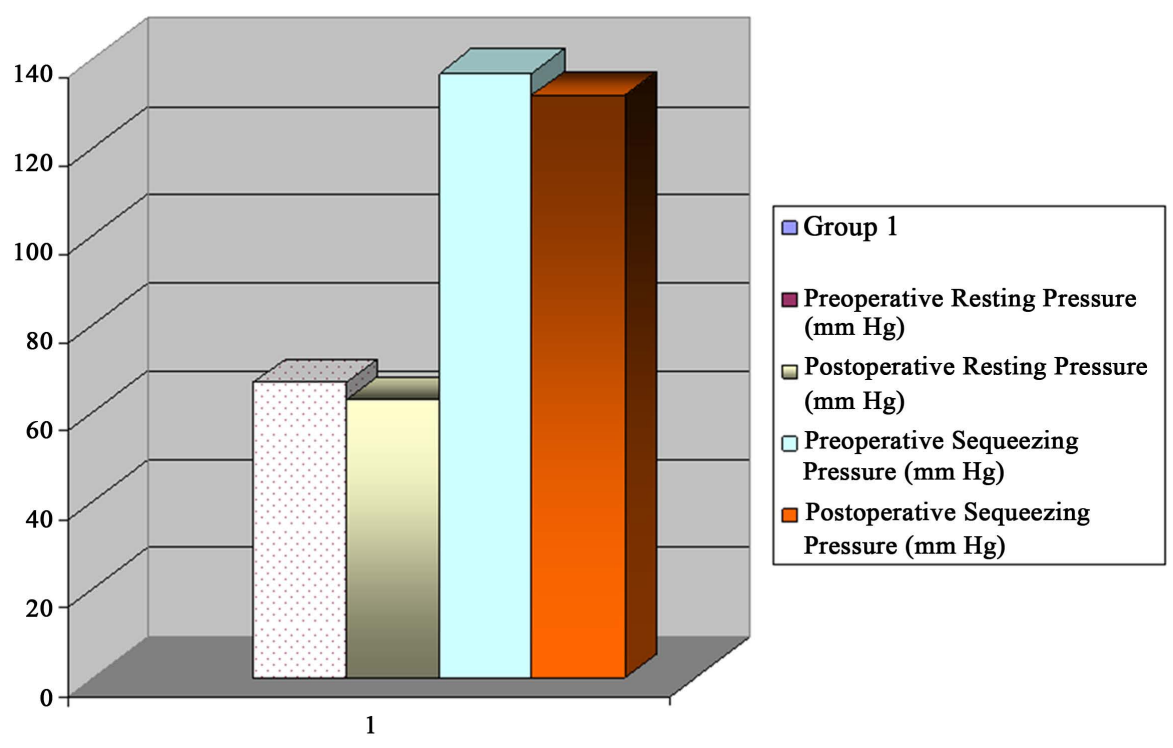

Figure 2. Pre- and postoperative pressure changes in-group $1(p>0.05)$.

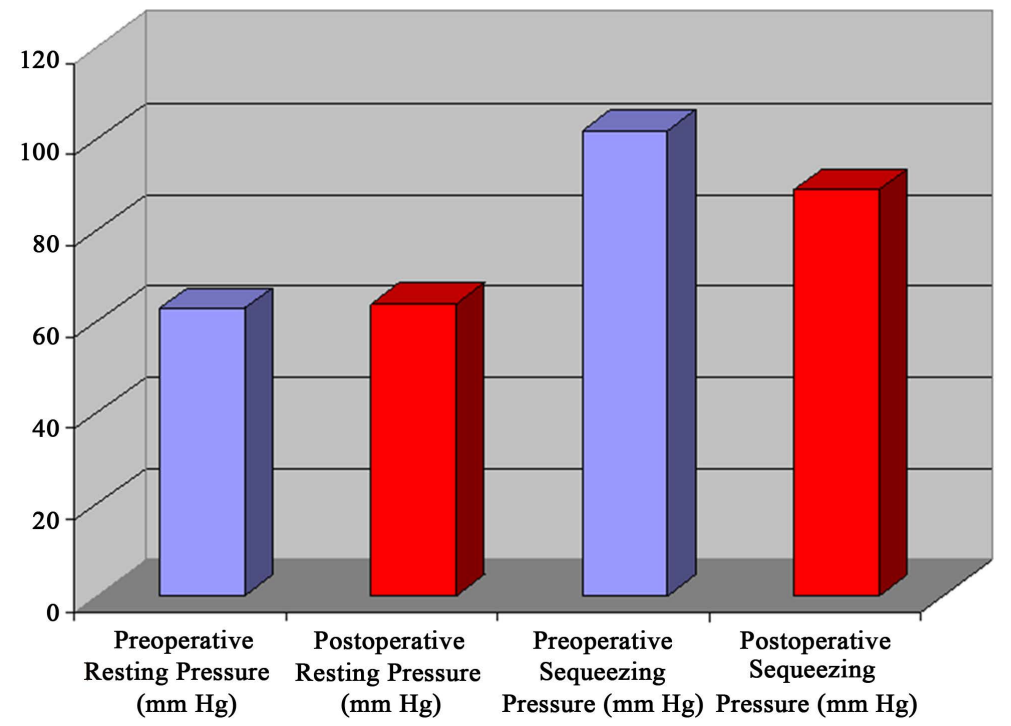

Figure 3. Pre- and postoperative pressure changes in-group $2(p<0.05)$.

Although some authors announced that similar incontinence and recurrence rates, as those of the cutting setons, are seen with the two-stage seton fistulotomy, the others strongly disagreed to this proposal [4] [8] [9]. The global rate of anal incontinence was $12 \%$ when any kind of cutting seton was used and healing rates in the retrospective observational studies identified vary between $33 \%$ and $100 \%$ [3]. However, retrospective observational studies have shown that healing rates for loose seton was varying between $33 \%$ and $100 \%$. Healing rate in our study is $100 \%$. But, this high healing rate may be due to the less number of patients in this study.

Pre- and postoperative values of mean resting and squeeze anal pressures $(\mathrm{mmHg}$ ) are shown in Figure 4. Both cutting and loose seton method was associated with somehow reductions in anal sphincter pressures and postoperative deformities of the anal canal even if internal sphincter had not been cut as a part of first operation [6] [10].

Incontinence rates in our study were $0 \%$ for solid and liquid stool and $2 \%(\mathrm{n}=1)$ for flatus in group $1 \%$ and $0 \%$ for solid and liquid stool and $12 \%(\mathrm{n}=6)$ for flatus in group 2 respectively. Incontinence rates of the patients were evaluated by using Wexner Score in our study [11]. Impaired continence reported in 0 to $62 \%$ of staged 


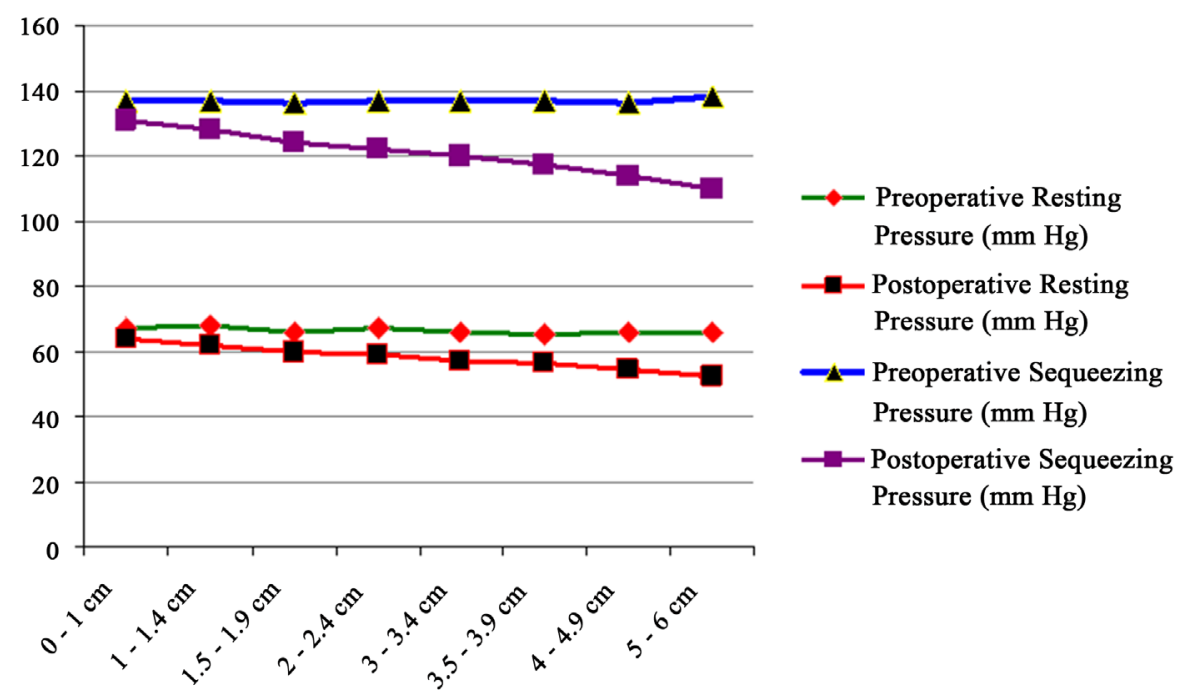

Figure 4. The relation of pressure changes and the length of fistula tract in group 2.

fistulotomy cases. Our results are comparable with the literature [3]. In theory, fibrosis formation during that period prevents retraction of the sphincter muscle behind the seton's advancement. However, as the length of time between tightening shortened, the impairment in postoperative anal pressure change increases. This is mostly due to rapidly cutting process which does not go along with synchronous wound healing process in the cutting surface of the fistula tract. However, to our knowledge, postoperative anal pressure changes in the relationship between the degree of caudal progression of loose seton has not been previously reported in the literature (Figure 4).

Recurrence rates around 25\% - 80\% have been reported in the literature with using long-term loose-seton techniques for complex perianal fistula [1] [12]. Although follow-up ranged between 12 - 36 months (mean, 25 months), there were no recurrences in our study This may be criticized, since the follow-up time was relatively short, but most of the recurrences occur in the first two-year period postoperatively. A great variability of anal continence impairment after seton placement has been published in the literature ranging between $0 \%$ and $70 \%$ [6] [8] [13]. These results might be due to different variety of seton materials and techniques described or perianal fistula characteristics and reported outcomes in the literature. So far, there is no uniform method used to study the endpoints from one series to another [14] [15].

The distance from the anal verge of the outer hole of the fistula to the fistula increases as its length increases the risk of developing anal incontinence. This suggests that management of the anal fistulas with cutting seton, may confine them to low anal fistulas. Although Whiteford et al. found that complex fistulas may be treated with a cutting seton technique [16], The Association of Coloproctologists of Great Britain and Northern Ireland (ACPGBI) recommended that a cutting seton should be used as the primary treatment only for a low transsphincteric fistula or as the secondary treatment for a low intrasphincteric fistula. Ritchie et al. showed that it would result in incontinence rates of 31\% - 53\% based on the fistula track site alone and the use of a cutting seton for anal fistula suggests that incontinence occurs in almost one in eight patients according to the available literature. We would therefore suggest that further consideration should be given to sphincter-preserving treatment in perianal fistula. This is the reason why we preferred loose seton in high transsphincteric fistula patients.

Patient satisfaction for the treatment for fistula-in-ano is closely associated with recurrence and the effects of anal incontinence on the lifestyle of the patient [6]. We examined their perception of the loose seton technique at every visit in the clinic during the follow-up period. All the patients participating to the study was satisfied with their treatment using this technique. The disadvantages of the loose seton placement is that healing of the fistula takes longer than cases treated with cutting seton or primary surgery and it causes pain to some degree especially in the first days of the treatment. However, pain and discomfort are controlled easily with oral analgesics and reduced consistently after ten days. We did not divide the internal anal sphincter with the intention of draining the intersphincteric space. Although, this site is considered as the presumed origin of cryptoglandular infection and this principle is considered as an important step in fistula surgery, the results after the internal sphincter division are worse than the failures at cutting the internal sphincter in the literature [17]. 
Our study had a few limitations. First, there are more numbers needed for last consideration about the effect of loose seton on anal incontinence. Second, we did not check if the changes of defecation frequency has any effect on migration of the seton during the study period. If so, it can be postulated that the number of the daily defecation may have a positive effect on loose seton movement around the anal sphincter mass. In a way, it is shown that loose seton can be used for high transsphincteric fistula which involved daily self rotation of the seton by $360^{\circ}$, which they called the progressive migration technique [18].

Third, seton material of choice used in our study was heavy silk, since it produces more inflammation than any other seton material. Comparisons of different type of seton materials other than heavy silk (rubber, silastic etc.) might be the subject of another study. This may answer whether slowly cutting feature of the seton or the inflammation created by the material's self structure might be the cause of clinical healing in fistula treatment.

\section{Conclusion}

Seton is still a useful technique in high perianal fistula surgery. Defining this technique as simply "loose" seton is a misnomer since it acts as a slowly cutting seton and results in $72 \%$ percent of progressive migration of the fistula tract caudally. Another interesting finding is, as the progressive migration of the loose seton loop increases, increased drops in pressure can be achieved in the postoperative period. Since the least drop in both resting and squeeze, anal sphincter pressures obtained in cases, which seton loop moved out spontaneously.

\section{References}

[1] Galis-Rozen, E., Tulchinsky, H., Rosen, A., Eldar, S., Rabau, M., Stepanski, A., Klausner, J.M. and Ziv, Y. (2010) Long-Term Outcome of Loose-Seton for Complex Anal Fistula: A Two-Centre Study of Patients with and without Crohn's Disease. Colorectal Disease, 12, 358-362. http://dx.doi.org/10.1111/j.1463-1318.2009.01796.x

[2] Eitan, A., Koliada, M. and Bickel, A. (2009) The Use of the Loose Seton Technique as a Definitive Treatment for Recurrent and Persistent High Trans-Sphincteric anal Fistulas: A Long-Term Outcome. Journal of Gastrointestinal Surgery, 6, 1116-1119. http://dx.doi.org/10.1007/s11605-009-0826-6

[3] Ritchie, E.R.D., Sackier, J.M. and Hodde, J.P. (2009) Incontinence Rates after Cutting Seton Treatment for Anal Fistula. Colorectal Disease, 11, 564-571. http://dx.doi.org/10.1111/j.1463-1318.2008.01713.x

[4] Thornton, M. and Solomon, M.J. (2005) Long-Term Indwelling Seton for Complex Anal Fistulas in Crohn’s Disease. Diseases of the Colon \& Rectum, 48, 459-463. http://dx.doi.org/10.1007/s10350-004-0830-6

[5] Davies, M., Harris, D., Lohana, P., Chandra Sekaran, T.V., Morgan, A.R., Beynon, J. and Carr, N.D. (2008) The Surgical Management of Fistula-in-Ano in a Specialist Colorectal Unit. International Journal of Colorectal Disease, 9, 833-838. http://dx.doi.org/10.1007/s00384-008-0444-x

[6] Garcia-Aguilar, J., Belmonte, C., Wong, D.W., Goldberg, S.M. and Madoff, R.D. (1998) Cutting Seton versus TwoStage Seton Fistulotomy in the Surgical Management of High Anal Fistula. British Journal of Surgery, 2, $243-245$. http://dx.doi.org/10.1046/j.1365-2168.1998.02877.x

[7] Lykke, A., Steendahl, J. and Wille-Jørgensen, P.A. (2010) Treating High Anal Fistulae with Slow Cutting Seton. Ugeskr Laeger, 7, 516-519.

[8] Theerapol, A., So, B.Y. and Ngoi, S.S. (2002) Routine Use of Setons for the Treatment of Anal Fistulae. Singapore Medical Journal, 43, 305-307.

[9] Buchanan, G.N., Owen, H.A., Torkington, J., Lunniss, P.J., Nicholls, R.J. and Cohen, C.R. (2004) Long-Term Outcome Following Loose-Seton Technique for External Sphincter Preservation in Complex Anal Fistula. British Journal of Surgery, 91, 476-480. http://dx.doi.org/10.1002/bjs.4466

[10] Perez, F., Arroyo, A., Serrano, P., Candela, F., Sanchez, A. and Calpena, R. (2005) Fistulotomy with Primary Sphincter Reconstruction in the Management of Complex Fistula-in-Ano: Prospective Study of Clinical and Manometric Results. Journal of the American College of Surgeons, 6, 897-903. http://dx.doi.org/10.1016/j.jamcollsurg.2004.12.015

[11] Jorge, J.M.N. and Wexner, S.D. (1993) Etiology and Management of Fecal Incontinence. Diseases of the Colon \& Rectum, 36, 779-797. http://dx.doi.org/10.1007/BF02050307

[12] Lentner, A. and Wienert, V. (1996) Long-Term, Indwelling Setons for Low Transsphincteric and Intersphincteric Anal Fistulas. Experience with 108 Cases. Diseases of the Colon \& Rectum, 10, 1097-1101. http://dx.doi.org/10.1007/BF02081407

[13] Williams, J.G., MacLeod, C.A., Rothenberger, D.A. and Goldberg, S.M. (1991) Seton Treatment of High Anal Fistulae. British Journal of Surgery, 78, 1159-1161. http://dx.doi.org/10.1002/bjs.1800781004

[14] Schouten, W.R. and Gosselink, M.P. (2005) Long Term Outcome Following Loose-Seton Technique for External 
Sphincter Preservation in Complex Anal Fistula. Techniques in Coloproctology, 1, 79.

[15] Toyonaga, T., Matsushima, M., Kiriu, T., Sogawa, N., Kanyama, H., Matsumura, N., Shimojima, Y., Hatakeyama, T., Tanaka, Y., Suzuki, K., et al. (2007) Factors Affecting Continence after Fistulotomy for Intersphincteric Fistula-inAno. International Journal of Colorectal Disease, 9, 1071-1075. http://dx.doi.org/10.1007/s00384-007-0277-z

[16] Whiteford, M.H., Kilkenny 3rd, J., Hyman, N., Buie, W.D., Cohen, J., Orsay, C., Dunn, G., Perry, W.B., Ellis, C.N., Rakinic, J., et al. (2005) Practice Parameters for the Treatment of Perianal Abscess and Fistula-in-Ano (Revised). Diseases of the Colon \& Rectum, 48, 1337-1342. http://dx.doi.org/10.1007/s10350-005-0055-3

[17] Vial, M., Parés, D., Pera, M. and Grande, L. (2010) Faecal Incontinence after Seton Treatment for Anal Fistulae with and without Surgical Division of Internal Anal Sphincter: A Systematic Review. Colorectal Disease, 12, 172-178. http://dx.doi.org/10.1111/j.1463-1318.2009.01810.x

[18] Subhas, G., Gupta, A., Balaraman, S., Mittal, V.K. and Pearlman, R. (2011) Non-Cutting Setons for Progressive Migration of Complex Fistula Tracts: A New Spin on an Old Technique. International Journal of Colorectal Disease, 26, 793-798. http://dx.doi.org/10.1007/s00384-011-1189-5 